\title{
Pulmonary berylliosis on corticosteroid therapy, with cavitating lung lesions and aspergillomata-report on a fatal
} case

\author{
Anthony A.J. O'Brien, David P. Moore and J.A. Brian Keogh
}

Department of Clinical Medicine, Meath Hospital, Dublin 8, Republic of Ireland

\begin{abstract}
Summary: A fatal case of pulmonary berylliosis in a 42 year old male is described. The patient was exposed to beryllium while working in a chemical plant over a 9 year period, and presented two years after ceasing such employment. The berylliosis was diagnosed on open lung biopsy in 1971. The patient was commenced on steroid therapy at that time. He suffered progressive dyspnoea from severe restrictive lung disease over the next 14 years. A chest X-ray of June 1985 revealed a lesion in the left upper lobe suggestive of a mycetoma. Before any therapy could be instituted he suffered a massive haemoptysis and died. Postmortem examination revealed two large mycetomata in the right and left upper lobes. Parenchymal histology showed evidence of chronic inflammation with non-caseating granulomata and the cavity wall showed localized invasion by Aspergillus fumigatus. It is possible that the long term steroid therapy with multiple boosters of treatment may have contributed to the development of the mycetoma. This is the first case report known to the authors of a fatal aspergilloma in association with chronic berylliosis treated with steroids.
\end{abstract}

\section{Introduction}

Acute lung disease secondary to beryllium exposure was first described in 1933.' The chronic form of the disease with a delayed onset was recognized in the United States in $1946 .{ }^{2}$ Over 800 cases of lung disease associated with beryllium exposure have now been recorded. ${ }^{3}$ The possible carcinogenicity of beryllium was alluded to in $1980{ }^{4}$ The clinical course in chronic berylliosis is usually that of progressive dyspnoea with deteriorating pulmonary function tests of either the obstructive or restrictive type with serial chest X-rays showing progressive pulmonary fibrosis. ${ }^{5}$ This case report describes the occurrence of a fatal aspergilloma in association with chronic berylliosis. Steroid therapy is the mainstay of treatment in chronic berylliosis but in this instance may have contributed to the development of the aspergilloma.

\section{Case report}

A 28 year old male presented in 1971 with progressive dyspnoea. The chest X-ray showed fibronodular disease throughout both lung fields. He had worked for 9 years in a chemical plant where beryllium was used as a hardening agent in alloys for use in electrical switches

Correspondence: J.A.B. Keogh, M.D., F.R.C.P.I. Accepted 4 March 1987. and presented two years after leaving that employment. Pulmonary function testing showed a forced expiratory volume in 1 second $\left(\mathrm{FEV}_{1}\right)$ of 1.5 litres and a forced vital capacity (FVC) of 2 litres (predicted being FEV, 3 litres and FVC 4 litres). Residual volume was 1.15 litres (predicted 1.45 litres). The total lung capacity was 3.18 litres (predicted 6.4). The total carbon dioxide transfer (TCO) at rest was 10.1 (predicted 21) and on exercise 13.2 (predicted 130). These findings were consistent with a severe restrictive lung defect. We proceeded to open lung biopsy. The lung parenchyma showed fibrotic scars and necrotic lung tissue. The cellular infiltrate consisted of lymphocytes and histiocytes and several noncaseating granulomata. Examination in polarized light revealed small needle-like crystals.

The tissue was analysed for beryllium content. The analysis was performed by atomic absorption spectrophotometry (Perkin-Elmer, type 603). The tissue weighed $0.5 \mathrm{~g}$ and its beryllium content measured $3.1 \mu \mathrm{g} / \mathrm{kg}$, wet weight, which is twelve times higher than levels quoted for normal lung tissue. ${ }^{3}$ In retrospect the patient fulfilled the criteria, since described by Hasan, ${ }^{3}$ for an adequate diagnosis of berylliosis, viz. (1) the establishment of beryllium exposure, (2) objective evidence of lower respiratory disease, (3) radiological evidence of interstitial fibronodular disease, (4) a restrictive or obstructive defect, (5) path-

(C) The Fellowship of Postgraduate Medicine, 1987 
ological changes consistent with beryllium disease and (6) the presence of beryllium in lung tissue. He was commenced on steroid therapy, $20 \mathrm{mg} /$ day in reducing doses and over the next 14 years his dyspnoea gradually worsened and this was paralleled by a deterioration in pulmonary function testing. He had had several admissions for worsening of his dyspnoea which required booster doses of steroids $1 \mathrm{mg} / \mathrm{kg}$, reducing slowly. The chest X-ray showed gradual deterioration with increasing fibronodular disease, but in addition in June 1985 a lesion was noted in the left upper lobe suggestive of a mycetoma (see Figure 1). Before any therapy could be introduced he presented with a massive haemoptysis and died one hour after admission. At autopsy the macroscopic findings were those of small scarred lungs with two large cavities in both apices measuring $10 \mathrm{~cm} \times 5 \mathrm{~cm}$ on the left and $8 \mathrm{~cm} \times 6 \mathrm{~cm}$ on the right. Both cavities contained mycetomata, subsequently shown to be secondary to Aspergillus fumigatus. The left cavity had eroded into the right upper lobe bronchus. Erosion of a bronchial vessel in this area was the cause of the massive haemoptysis and death. The parenchymal lung tissue was similar to the initial biopsy of 1971 with cellular infiltration and fibrotic scarring. No evidence of extra-thoracic dissemination of berylliosis was found at autopsy.

\section{Discussion}

Our case demonstrates diffuse pulmonary berylliosis, progressive in nature despite steroid therapy. The cause of death was pulmonary aspergillosis in a mycetoma with vascular invasion. The occurrence of aspergilloma in sarcoidosis, a condition closely linked to berylliosis in its pathology and clinical manifestations, has been described. ${ }^{6}$ Cavitatory disease with mycetoma has not been previously described in a case of chronic berylliosis. In this case report the patient had only localized invasion with aspergillus from the

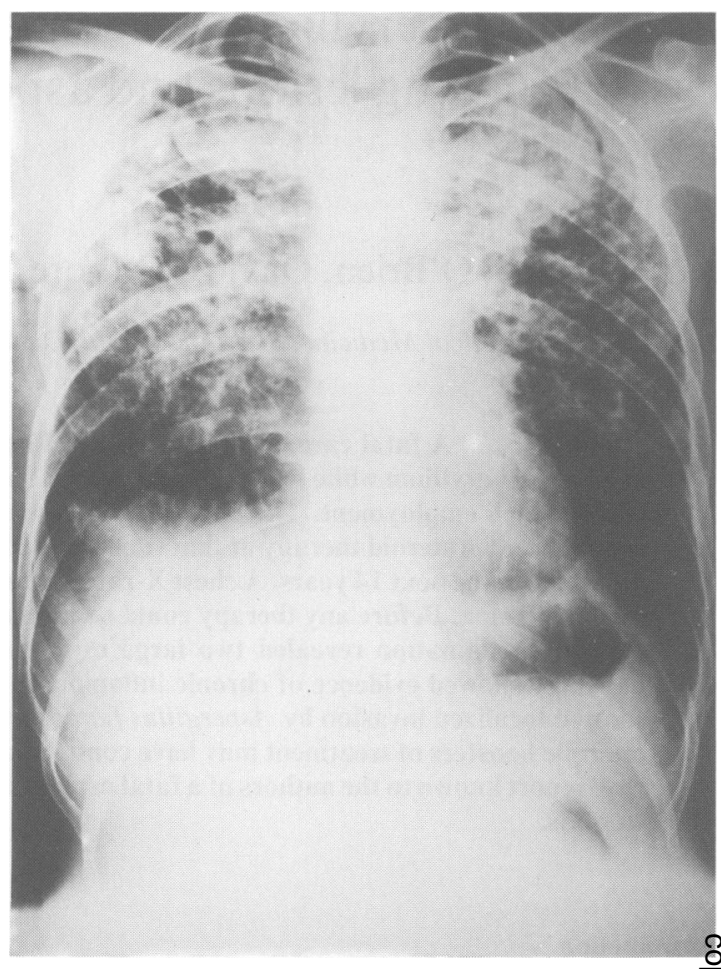

Figure 1 Chest $X$-ray showing changes of chronic berylliosis.

mycetoma but this was undoubtedly the cause of death.

Corticosteroids have been implicated in the aetiology of invasive pulmonary aspergillosis, especially in patients where cavitatory disease exists. ${ }^{7}$ Clearly, corticosteroid therapy failed to halt the progression of the fibrotic lung disease and probably predisposed the patient to fungal lung disease. We feel that vigilance should be observed in the use of high dose steroids in this clinical situation. 


\section{References}

1. Weber, H.H. \& Engelhardt, W.E. Uber Eine Apparatur Zur Erzengung Niedrige Staubkonzentrationen Von Grosser Konstanz Und Eine Methode Zur Mikrogravinctrischen Staubbestimmung. Anwendung Bei Der Undersuchung Von Stauben Aus Der Beryllium Gewinnung. Zentralb Gewerbehyg Unfallerhab 1933, 10: 41-47.

2. Hardy, H.L. \& Tabershaw, I.R. Delayed chemical pneumonitis occurring in workers exposed to beryllium compounds. J Industr Hyg Tox 1946, 28: 197-211.

3. Hasan, F.M. \& Kazemi, H. Chronic beryllium disease: a continuing epidemiological hazard. Chest 1974, 65: 289293.
4. Groth, D.H. Carcinogenicity of beryllium: review of the literature. Environ Res 1980; 21: 56-62.

5. Constantinidis, K. Acute and chronic beryllium disease. Br J Clin Prac 1978, 32: 127-136.

6. Waldhorn, R.E., Tsou, U. \& Kerwin, D.M. Invasive pulmonary aspergillosis associated with aspergilloma in sarcoidosis. South Med J 1983, 76: 251-253.

7. Williams, D.P., Krick, J.A. \& Remington, J.S. Pulmonary infection in the compromised host. Part I. Am Rev Respir Dis 1976 114: 359-394. 